\title{
Various designs for a production unit of 35 sows with extension possibilities Consequences on labour, investments and profit earning capacity
}

\author{
P. ROUSSEAU, O. THÉLOT, M. FERRADINI \\ I.T.P., Région Ouest, La Motte-au-Vicomte \\ B.P. 3, 35650 Le Rhen (France)
}

The authors give a survey of a study made to analyse different production models for a herd size of 35 sows.

Three types of piggeries were suggested:

- little expensive buildings, but requiring much labour

- more expensive buildings requiring less labour

-. technically excellent buildings with moderate operating costs.

Til management systems were the following:

- 3 batches of 12 sows (interval of 49 d);

-7 batches of 5 sows (interval of $27 \mathrm{~d}$ ).

and two methods used in the farrowing houses: either with or without post-weaning transfer of the piglets.

Results were the following:

-- The system without post weaning transfer slightly increased the production costs.

-- Normal labour payment in connection with "ready-for-use " buildings required a pro-

ductivity of I8-2 I bacon pigs per sow and per year.

-.. Ploughing back of profits by participation of the farmer in the construction of buildings

led to the same income as with " ready-for-use " buildings but with I-I.5 bacon pigs less per sow and per year.

... Use of straw litter reduced the investments by about $30 \mathrm{p}$. roo, but increased labour requirements.

\section{Modernization of pig production: \\ The rationalization of pig herd management and its limits}

\author{
F. COLSON
}

I.N.R.A., Laboratoire d'Etudes Économiques sur les I.A.A.

Chemin de la Géraudière, 44072 Nantes Cedex (France)

A survey of the results obtained after ten years of national assistance in the modernization of pig production shows that:

- the development of large herds is very low;

- the number of small herds although decreasing fastly is still large,

- a restricted number of farmers nostly combining pig and cattle production are developing intensive management systems. Most of these farmers belong to producers cooperations.

This development of the production has been achieved according to a dominant "technicoeconomic "model, characterized by expensive investments and purchase of livestock feedstuffs based on cereals and soybean.

Owing to a fast improvment of the herd performance, French pig production has reached the same level as that of the other E.E.C. countries. However, the prolonged maintenance of M.C.M. has led to a marked degradation in France of the ratio: price of pigs, price of livestock feeds and bence to a reduction of the national production potential.

The inflation and economic crisis have deeply changed the production conditions emphasizing the economic fragility of the most intensive production units which require a very large capital. 